ARTICLE

Received 31 Dec 2015 | Accepted 27 May 2016 | Published 5 Jul 2016

DOl: $10.1038 /$ ncomms12079

OPEN

\title{
End-Cretaceous extinction in Antarctica linked to both Deccan volcanism and meteorite impact via climate change
}

\author{
Sierra V. Petersen ${ }^{1}$, Andrea Dutton ${ }^{2} \&$ Kyger C. Lohmann ${ }^{1}$
}

The cause of the end-Cretaceous ( $\mathrm{KPg}$ ) mass extinction is still debated due to difficulty separating the influences of two closely timed potential causal events: eruption of the Deccan Traps volcanic province and impact of the Chicxulub meteorite. Here we combine published extinction patterns with a new clumped isotope temperature record from a hiatus-free, expanded KPg boundary section from Seymour Island, Antarctica. We document a $7.8 \pm 3.3^{\circ} \mathrm{C}$ warming synchronous with the onset of Deccan Traps volcanism and a second, smaller warming at the time of meteorite impact. Local warming may have been amplified due to simultaneous disappearance of continental or sea ice. Intra-shell variability indicates a possible reduction in seasonality after Deccan eruptions began, continuing through the meteorite event. Species extinction at Seymour Island occurred in two pulses that coincide with the two observed warming events, directly linking the end-Cretaceous extinction at this site to both volcanic and meteorite events via climate change.

\footnotetext{
${ }^{1}$ Department of Earth \& Environmental Sciences, University of Michigan, 2534 C.C. Little Building, 1100 North University Avenue, Ann Arbor, Michigan 48109, USA. ${ }^{2}$ Department of Geological Sciences, University of Florida, 241 Williamson Hall, PO Box 112120, Gainesville, Florida 32611, USA. Correspondence and requests for materials should be addressed to S.V.P. (email: sierravp@umich.edu).
} 
T he cause of the Cretaceous-Paleogene (KPg) mass extinction remains controversial due to difficulties in separating the influence of two closely timed potential causal events. Some suggest that the eruption of the massive Deccan Traps volcanic province in India caused species extinction ${ }^{1}$ through trace metal toxicity ${ }^{2}$ or negative effects of volatiles emitted during the eruption (for example, $\left.\mathrm{CO}_{2}, \mathrm{SO}_{2}\right)^{3}$. Others cite the impact of the massive Chicxulub meteorite as the cause ${ }^{4,5}$. Recent work has suggested that the impact event might have triggered and accelerated eruption of the Deccan Traps $s^{6,7}$, further complicating the cause-effect relationship. Distinguishing between the effects of these two potential causal events can be difficult because many $\mathrm{KPg}$ boundary (KPB) sites have hiatuses, insufficient temporal resolution, and lack of species continuity across the boundary.

Seymour Island, Antarctica $\left(64^{\circ} 17^{\prime} \mathrm{S}, 56^{\circ} 45^{\prime} \mathrm{W}\right)$ is particularly well-suited for studying the KPB interval due to its expanded section, continuous sedimentation, and abundant, exceptionally preserved macrofossils, including some species and genera that survive across the $\mathrm{KPB}^{8,9}$. Previous efforts to link temperature change and biotic turnover at Seymour Island relied on untested assumptions about the value and stability of the oxygen isotopic composition of seawater $\left(\delta^{18} \mathrm{O}_{\mathrm{w}}\right)$ to calculate temperature ${ }^{10}$. These assumptions can now be avoided (and tested) using the carbonate clumped isotope paleothermometer, a new proxy that can measure temperature independent of $\delta^{18} \mathrm{O}_{\mathrm{w}}$, and can therefore directly calculate $\delta^{18} \mathrm{O}_{\mathrm{w}}$ for each sample ${ }^{11}$.

Here we present a record of high latitude ocean temperature and $\delta^{18} \mathrm{O}_{\mathrm{w}}$ from Seymour Island that covers the last few million years of the Cretaceous and crosses the KPB (from $\sim 69-65.5 \mathrm{Ma}$ ), measured on well-preserved bivalve shells. We find evidence of climate change at the onset of Deccan volcanism and again at the KPB that align with two previously identified pulses of extinction ${ }^{10}$, indicating the complete end-Cretaceous extinction at this site is due to the combined effects of the volcanic and meteorite kill mechanisms.

\section{Results}

Stable and clumped isotope analysis of fossil bivalves. Twentynine well-preserved shells, representing five species of bivalve (Lahillia larseni, Cucullaea antarctica, Cucullaea ellioti, Eselaevitrigonia regina and Nordenskjoldia nordenskjoldi) were selected from the Zinsmeister collection ${ }^{9}$, and were analysed for $\delta^{18} \mathrm{O}, \quad \delta^{13} \mathrm{C}$, and the clumped isotope composition, $\Delta_{47}$ (see Methods). These shells represent the best-preserved individuals from a larger sample set of 116 shells that were analysed for only $\delta^{18} \mathrm{O}$ and $\delta^{13} \mathrm{C}$ (see Methods). Shell preservation was determined by X-ray diffraction, cathodoluminescence and trace element screening (see Methods). $\delta^{18} \mathrm{O}_{\mathrm{w}}$ values were calculated for each clumped isotope sample using the $\Delta_{47}$-derived temperature, measured $\delta^{18} \mathrm{O}$ of the shell, and an equilibrium temperature relationship for aragonite ${ }^{12}$. Shells come from Units 9 and 10 of the López de Bertodano Formation, which represent an outer to inner shelf environment with a water depth of $<200 \mathrm{~m}$ (ref. 8). Most shells were sampled in two locations, the umbo (hinge) and the ventral margin (see Methods). An age model was constructed using published magnetostratigraphic data ${ }^{10}$ and was corroborated with published ${ }^{13}$ and new ${ }^{87} \mathrm{Sr} /{ }^{86} \mathrm{Sr}$ measurements (see Methods).

Cretaceous-Paleogene temperature at Seymour Island. The $\Delta_{47}$-derived temperatures for each species and shell position are shown in Fig. 1a. Temperatures warm from $\sim 5^{\circ} \mathrm{C}$ to $\sim 14^{\circ} \mathrm{C}$ between 68.7 and $67.8 \mathrm{Ma}$. After $\sim 1 \mathrm{Myr}$ of sustained warm $\left(\sim 9-12{ }^{\circ} \mathrm{C}\right)$ temperatures, a gradual cooling back to $\sim 4{ }^{\circ} \mathrm{C}$ occurs from 66.9 to $66.25 \mathrm{Ma}$. Approximately $150 \mathrm{kyr}$ before the
KPg boundary, a marked warming of $\sim 7.8 \pm 3.3^{\circ} \mathrm{C}$ occurs. After the initial warming, temperatures decline until a second smaller warming pulse occurs at the KPB $\left(1.1 \pm 2.7^{\circ} \mathrm{C}\right)$ followed by continued decline until pre-event levels are reached $\sim 200-400 \mathrm{kyr}$ after the initial spike. Although the second warming is minor when comparing the horizon means, individual samples reach temperatures near those seen at the peak of the earlier, larger warming spike (Fig. 1a).

The mean ocean temperature for the entire section is $7.7 \pm 3.4^{\circ} \mathrm{C}$ ( 1 s.d.), consistent with a terrestrial temperature estimate of $7^{\circ} \mathrm{C}$ from fossil wood ${ }^{14}$ and a soil temperature estimate of $10-13{ }^{\circ} \mathrm{C}$ from branched tetraethers ${ }^{15}$. Maastrichtian ocean temperatures from Seymour Island have been previously estimated at anywhere from 5 to $16^{\circ} \mathrm{C}$ based on $\delta^{18} \mathrm{O}$ of micro- and macro-fossils ${ }^{10,16-19}$, but these estimates assume a fixed $\delta^{18} \mathrm{O}_{\mathrm{w}}$ value, which is not appropriate for this location (see below). The long-term temperature pattern is mirrored in all species and shell positions (Fig. 1a; Supplementary Fig. 1), and is robust across different methods of calculating horizon means (see Methods; Supplementary Fig. 2). The pattern is consistent with terrestrial climate reconstructions based on fungal palynomorphs and pollen grains, which document warm, humid conditions during Chron $30 \mathrm{~N}$, bracketed by cooler conditions before and after $^{20}$. Similar pre-KPB warming in Chron 29R, albeit of lower magnitude, has been seen before, with $\sim 5^{\circ} \mathrm{C}$ of warming observed in a terrestrial section in North America $^{21}$ and $2-3^{\circ} \mathrm{C}$ of warming recorded in multiple openmarine records ${ }^{22-24}$.

Patterns in position-specific isotopic and temperature data. Position-specific measurements of the umbo and ventral margin can provide additional information about seasonal variability. Within a single shell, the difference between the temperature recorded in the umbo and ventral margin can be as great as $7-8^{\circ} \mathrm{C}$ or as little as $0^{\circ} \mathrm{C}$. All specimens of Lahillia before the warming spike show consistent offsets between the two positions, with temperatures $\sim 3-9{ }^{\circ} \mathrm{C}$ warmer, $\delta^{18} \mathrm{O}_{\mathrm{w}}$ values $\sim 1-3 \%$ higher, and $\delta^{13} \mathrm{C}$ values $\sim 1-4 \%$ higher in the umbo than in the ventral margin (Fig. 2; Supplementary Fig. 3). In contrast, Cucullaea specimens have $\delta^{13} \mathrm{C}$ values $\sim 2-6 \%$ lower in the umbo than in the ventral margin (Fig. 2b). Position-specific differences in temperature and $\delta^{18} \mathrm{O}_{\mathrm{w}}$ for Cucullaea are less consistent, but are generally in the opposite direction of those seen in Lahillia (Fig. 2; Supplementary Fig. 4).

We suggest these position-specific differences in temperature, $\delta^{18} \mathrm{O}_{w}$, and $\delta^{13} \mathrm{C}$ are due to different seasonal aliasing early and late in the life cycle of the bivalve. Bivalves cease shell growth during reproduction ${ }^{25}$, or when under thermal stress (either too $\operatorname{hot}^{26}$ or cold ${ }^{27}$, depending on the taxon), and shell growth slows and becomes more seasonally restricted later in life ${ }^{28}$. For example, Eocene-age Cucullaea shells from Seymour Island were shown to cease growth during the warmest months of each year, based on high-resolution $\delta^{18} \mathrm{O}$ measurements ${ }^{26}$. The umbo, which represents early life, should therefore average a larger number of months than the ventral margin, which represents later life when shell growth slows and ceases during reproduction months. For Lahillia, the cooler temperature recorded in the ventral margin suggests that shell growth ceased in summer later in life. For Cucullaea, the opposite is true, with shell growth biased towards warmer months later in life. The magnitude of the temperature difference between the two positions $\left(0-9^{\circ} \mathrm{C}\right)$ represents a minimum estimate of the seasonal amplitude at this latitude. Position-specific differences can also be seen in $\delta^{18} \mathrm{O}$ and $\delta^{13} \mathrm{C}$ in shells not measured for clumped isotopes (Supplementary Figs 5-7). 

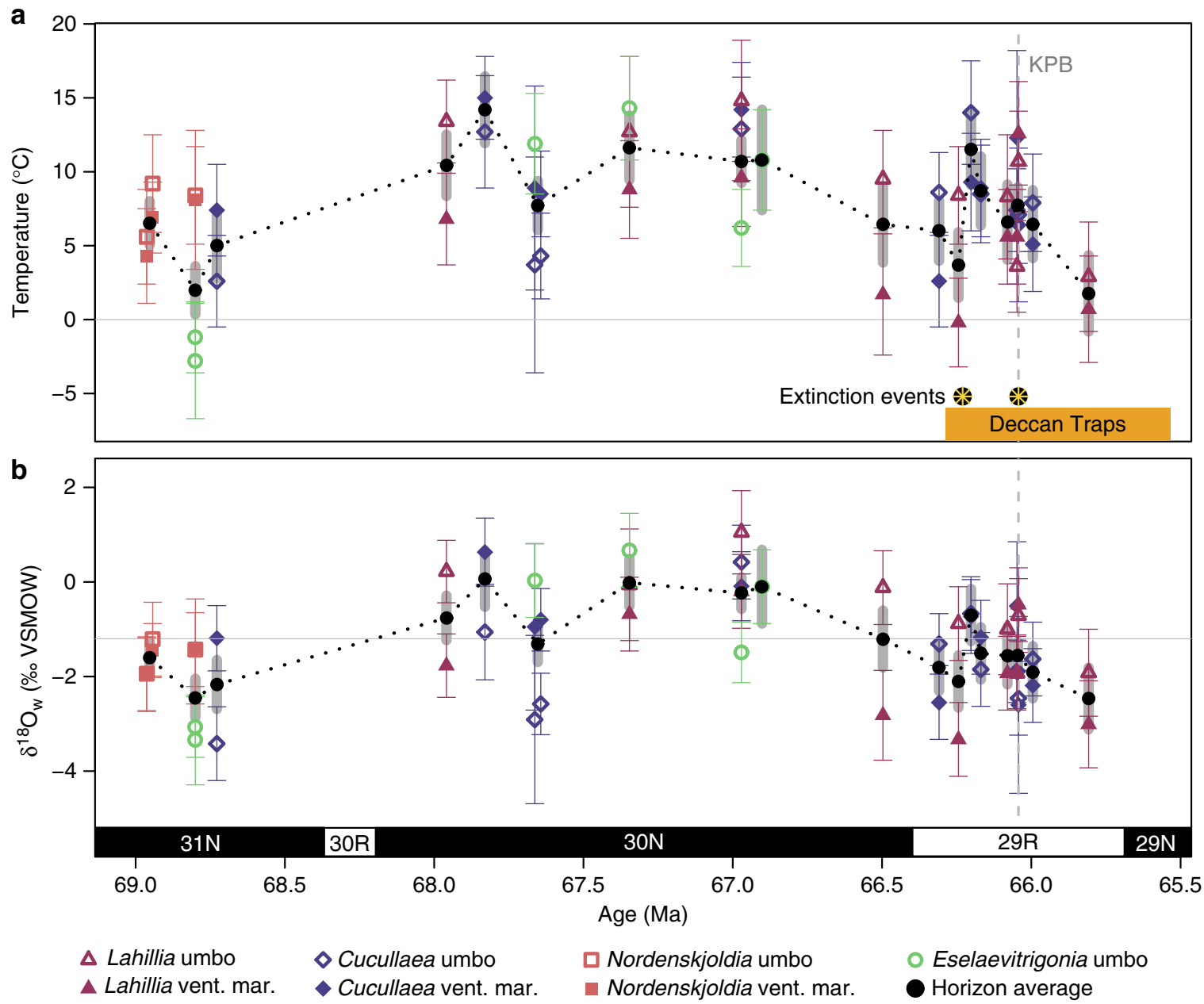

Figure 1 | Late Cretaceous temperature and $\boldsymbol{\delta}^{\mathbf{1 8}} \mathbf{O}_{\mathbf{w}}$ at Seymour Island. (a) $\Delta_{47}$-derived temperature and (b) $\delta^{18} \mathrm{O}_{w}$ versus age. The timing of Deccan Traps volcanism ${ }^{7,33}$ (orange rectangle) and two extinction pulses ${ }^{10}$ (black/orange stars) are shown for comparison. Coloured error bars on individual points represent 1 s.e. of the mean of many replicates or the long-term reproducibility of carbonate standards, whichever is larger (see Methods). Horizon averages in $\mathbf{a}, \mathbf{b}$ were calculated as the inverse variance weighted mean, to account for variable reproducibility of samples, with thick grey error bars showing the inverse variance weighted error on the mean (see Methods). Black line connecting horizon means is dashed to represent extrapolation of temperature and $\delta^{18} \mathrm{O}_{\mathrm{w}}$ trends between measured horizons. Samples within $\pm 3.5 \mathrm{~m}$ stratigraphic position of another sample were combined into a single horizon for horizon means (see Methods). Grey horizontal line in a represents the freezing point $\left(0^{\circ} \mathrm{C}\right)$ and in $\mathbf{b}$ represents the ice free, latitude-adjusted seawater value of $-1.2 \%$ (ref. 30). Vertical grey dashed line denotes the KPg boundary (labelled KPB) ${ }^{34}$. Age model construction is described in Methods. Data for this figure can be found in Supplementary Data 5 and 6.

High variability in $\delta^{18} \mathrm{O}_{\mathrm{w}}$ within and between shells. Individual sample $\delta^{18} \mathrm{O}_{\mathrm{w}}$ values vary from -3.4 to $+1.0 \%$ through the section, and $\delta^{18} \mathrm{O}_{\mathrm{w}}$ is highly correlated to temperature (Fig. 1; Supplementary Fig. 8; Supplementary Discussion). The mean $\delta^{18} \mathrm{O}_{\mathrm{w}}$ value for the entire section is $-1.3 \pm 0.8 \%$ ( 1 s.d.). This agrees with the value predicted for an ice-free world $(-1.0 \%$; ref. 29) or for an ice-free world adjusted for the modern latitudinal isotopic gradient $(-1.2 \%$; ref. 30$)$, two $\delta^{18} \mathrm{O}_{\mathrm{w}}$ values typically assumed when converting carbonate $\delta^{18} \mathrm{O}$ to temperature. However, the large range and temporal variability in $\delta^{18} \mathrm{O}_{w}$, on the order of $\pm 1-2 \%$, suggests that the typical assumptions of constant $\delta^{18} \mathrm{O}_{\mathrm{w}}$ are incorrect for this location and introduce bias into temperatures calculated from $\delta^{18} \mathrm{O}$. Figure 3 compares the clumped isotope temperature record to temperature calculated from carbonate $\delta^{18} \mathrm{O}$ for shells from this study and from Tobin et al. ${ }^{10}$, assuming a constant $\delta^{18} \mathrm{O}_{\mathrm{w}}$ value of $-1.0 \%$. Both $\delta^{18} \mathrm{O}$-derived temperature records fail to capture the temperature structure seen in the clumped isotope record on both million-year and sub-million-year timescales. For example, both $\delta^{18} \mathrm{O}$-derived temperature records do not identify the coldest temperatures $\left(<5^{\circ} \mathrm{C}\right)$ around $68.8,66.4$ and $65.7 \mathrm{Ma}$ (Fig. 3). This is because the positively correlated variation in temperature and $\delta^{18} \mathrm{O}_{\mathrm{w}}$ have opposite effects on shell $\delta^{18} \mathrm{O}$, masking both signals and resulting in minimally varying, intermediate $\delta^{18} \mathrm{O}$ values. If a fixed value for $\delta^{18} \mathrm{O}_{\mathrm{w}}$ is assumed, the resulting $\delta^{18} \mathrm{O}$-derived temperature record has only around half the variability of the 'true' clumped isotope temperature record, which allows for variations in $\delta^{18} \mathrm{O}_{\mathrm{w}}\left(7^{\circ} \mathrm{C}\right.$ versus $12.5^{\circ} \mathrm{C}$ temperature range for shells from this study). Therefore, temperatures derived from $\delta^{18} \mathrm{O}$ of micro- and macro-fossils from Seymour Island that assume a fixed $\delta^{18} \mathrm{O}_{\mathrm{w}}$ value $\mathrm{e}^{10,16-19}$ should only be taken on average, and any time series that do not account for changing $\delta^{18} \mathrm{O}_{\mathrm{w}}$ should be treated with caution and assumed to underestimate true temperature variability.

\section{Discussion}

We propose that the observed $\delta^{18} \mathrm{O}_{\mathrm{w}}$ variability reflects the influence of continental runoff. Precipitation over land is more depleted in ${ }^{18} \mathrm{O}$ than ocean water, sometimes by more than 

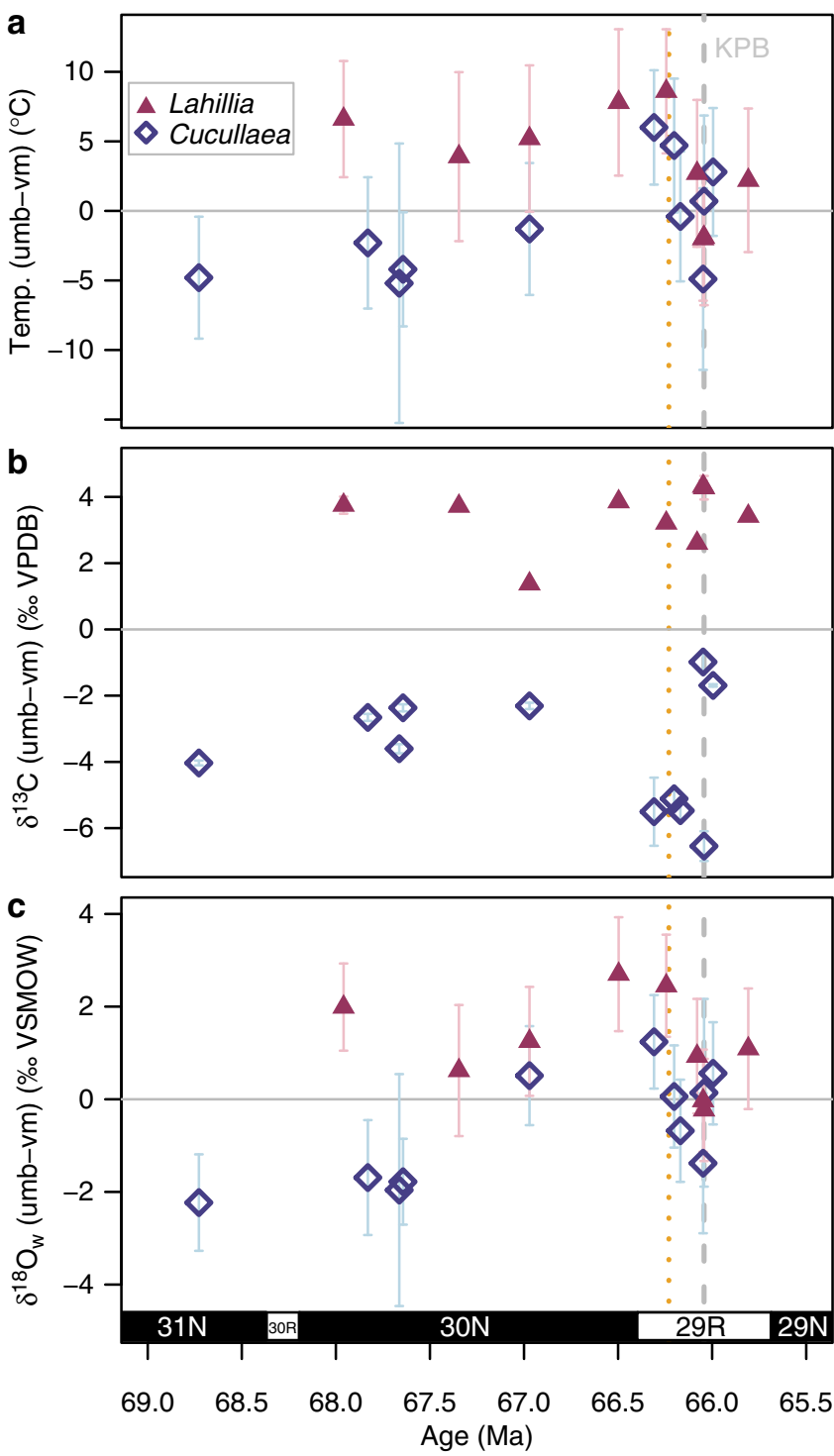

Figure 2 | Position-specific differences. Differences in (a) temperature, (b) $\delta^{13} \mathrm{C}$ and (c) $\delta^{18} \mathrm{O}_{\mathrm{w}}$ for Lahillia and Cucullaea versus age. All differences calculated as the umbo minus the ventral margin value (umb-vm), with the horizontal grey line at 0 representing no difference between positions. Error bars are 1 s.e. for temperature and $\delta^{18} \mathrm{O}_{w}$ and 1 s.d. for $\delta^{13} \mathrm{C}$, propagated through the difference calculation. Lahillia consistently shows warmer temperatures, and higher $\delta^{13} \mathrm{C}$ and $\delta^{18} \mathrm{O}_{\mathrm{w}}$ in the umbo relative to the ventral margin ( + difference). Cucullaea generally shows the opposite, with warmer temperatures, and higher $\delta^{13} \mathrm{C}$ and $\delta^{18} \mathrm{O}_{\mathrm{w}}$ in the ventral margin relative to the umbo (- difference), although this pattern is less consistent. After the pre-KPB warming spike, the position-specific differences in temperature and $\delta^{18} \mathrm{O}_{w}$ for both Lahillia and Cucullaea decrease to within error of zero and remain low until the end of the study interval. Differences in $\delta^{13} \mathrm{C}$ remain fairly constant through the section. Vertical grey dashed line represents the KPg boundary (labelled KPB) ${ }^{34}$ and orange dotted line represents the timing of the first extinction event ${ }^{10}$. Age model construction is described in Methods.

$10-15 \%$, so any appreciable contribution of runoff would decrease $\delta^{18} \mathrm{O}_{\mathrm{w}}$ values in shelf waters. The correlation between $\delta^{18} \mathrm{O}_{\mathrm{w}}$ and temperature, with the coldest temperatures correlating with the lowest $\delta^{18} \mathrm{O}_{\mathrm{w}}$ values, suggests a climatological control on runoff delivery. Precipitation becomes more depleted in ${ }^{18} \mathrm{O}$ as air temperature decreases. In addition, colder temperatures would promote the accumulation of snowpack in winter and the concentrated delivery of isotopically depleted meltwater during the spring melt, reducing $\delta^{18} \mathrm{O}_{\mathrm{w}}$ below expected open-marine values. Terrestrial carbon, depleted in $\delta^{13} \mathrm{C}$ relative to marine carbon, could accompany the spring melt, explaining the co-occurrence of low $\delta^{18} \mathrm{O}_{\mathrm{w}}$ and low $\delta^{13} \mathrm{C}$. This hypothesized seasonal meltwater delivery is consistent with the temperature differences observed between positions in Lahillia (Cucullaea), with lower (higher) $\delta^{18} \mathrm{O}_{\mathrm{w}}$ and $\delta^{13} \mathrm{C}$ in the ventral margin, the position skewed more towards colder (warmer) months.

The coldest temperatures recorded in the Seymour Island section (at 68.8, 66.4 and 65.7 Ma) are near the freezing point, implying the possibility of sea ice formation near Seymour Island. Dinoflagellate cyst abundance has previously suggested that sea ice formed at this time ${ }^{20}$. With temperatures near freezing at sea level at the tip of the Antarctic Peninsula, the interior of Antarctica was likely cold enough to sustain yearround glaciers, particularly at high elevation. Global sea level reconstructions record two sea level falls in the late Maastrichtian $(\mathrm{KMa} 4 \text { and } \mathrm{KMa} 5)^{31}$. Sequence boundaries occur at 66.8 and 68.8 Ma, with sea level minima closely following ${ }^{31}$. The close temporal alignment of sea level lowstands and coldest Antarctic temperatures suggests that the observed sea level fluctuations could be driven by continental ice accumulation on Antarctica.

The $\sim 8^{\circ} \mathrm{C}$ pre-KPB warming observed in the Seymour Island record is larger than similar warming events seen at other marine sites $^{22-24}$. If sea ice or continental ice were present during the coldest interval immediately preceding the warming spike (66.5-66.3 Ma), the disappearance of this ice during warming could accentuate local climate change at Seymour Island through the ice-albedo feedback, the same process that is currently amplifying anthropogenic climate change in the Arctic by roughly a factor of $\mathrm{two}^{32}$. In addition, if this warming was accompanied by melting of continental ice, the reduction in global seawater $\delta^{18} \mathrm{O}_{\mathrm{w}}$ would mute marine temperature change calculated from $\delta^{18} \mathrm{O}$ assuming constant $\delta^{18} \mathrm{O}_{\mathrm{w}}$ (refs 22-24). One terrestrial record derived from plant assemblages, which are immune to changing $\delta^{18} \mathrm{O}_{\mathrm{w}}$ values, indicated $\mathrm{a} \sim 5^{\circ} \mathrm{C}$ warming at this time $e^{21}$, larger than the $2-3^{\circ} \mathrm{C}$ observed at open-marine sites ${ }^{22-24}$. $\delta^{18} \mathrm{O}$-derived temperature records from Seymour Island ${ }^{10}$ also record a pre-KPB warming of $\sim 5^{\circ} \mathrm{C}$, but the warming event begins earlier, is more gradual, and is of lower magnitude because this proxy method does not account for concurrent increases in $\delta^{18} \mathrm{O}_{\mathrm{w}}$ at this time (Fig. 3).

The majority of Deccan Traps volcanism occurred during Chron 29R, and the oldest formation (Jawhar) has been dated near its base to $66.288 \pm 0.027 \mathrm{Ma}$ (ref. 33) and $66.38 \pm 0.05 \mathrm{Ma}$ (ref. 34) using two different dating methods. The temporal alignment of the pre-KPB warming event at Seymour Island with the onset of Deccan Traps volcanism suggests a genetic link between volcanic release of $\mathrm{CO}_{2}$ and the abrupt increase in temperature. The eruptions that occurred between the onset of Chron 29R volcanism and the KPg boundary emitted anywhere from 270 to 900 p.p.m. $\mathrm{CO}_{2}$ (assuming $14 \mathrm{Tg} \mathrm{CO}_{2}$ emitted per $\mathrm{km}^{3}$ lava erupted ${ }^{35}$, and all $\mathrm{CO}_{2}$ remaining in the atmosphere, see Methods) onto a background atmospheric concentration of $\sim 360-380$ p.p.m. (ref. 36). The timing of transient increases in marine carbonate dissolution driven by the emitted $\mathrm{CO}_{2}$ suggest the main phase of degassing took place beginning at the onset of Chron 29R, lasting less than $200 \mathrm{kyr}$ (ending before the $\mathrm{KPB})^{37}$. Using the same volume-to- $\mathrm{CO}_{2}$ conversion, the remaining (post-KPB) volcanism potentially emitted another $825-900$ p.p.m. The magnitude of the second, weaker warming event at the $\mathrm{KPB}$ only appears as $1.1^{\circ} \mathrm{C}$ in the horizon mean, but individual samples show a potentially larger warming (Fig. 1a). Though the volume of lava erupted 


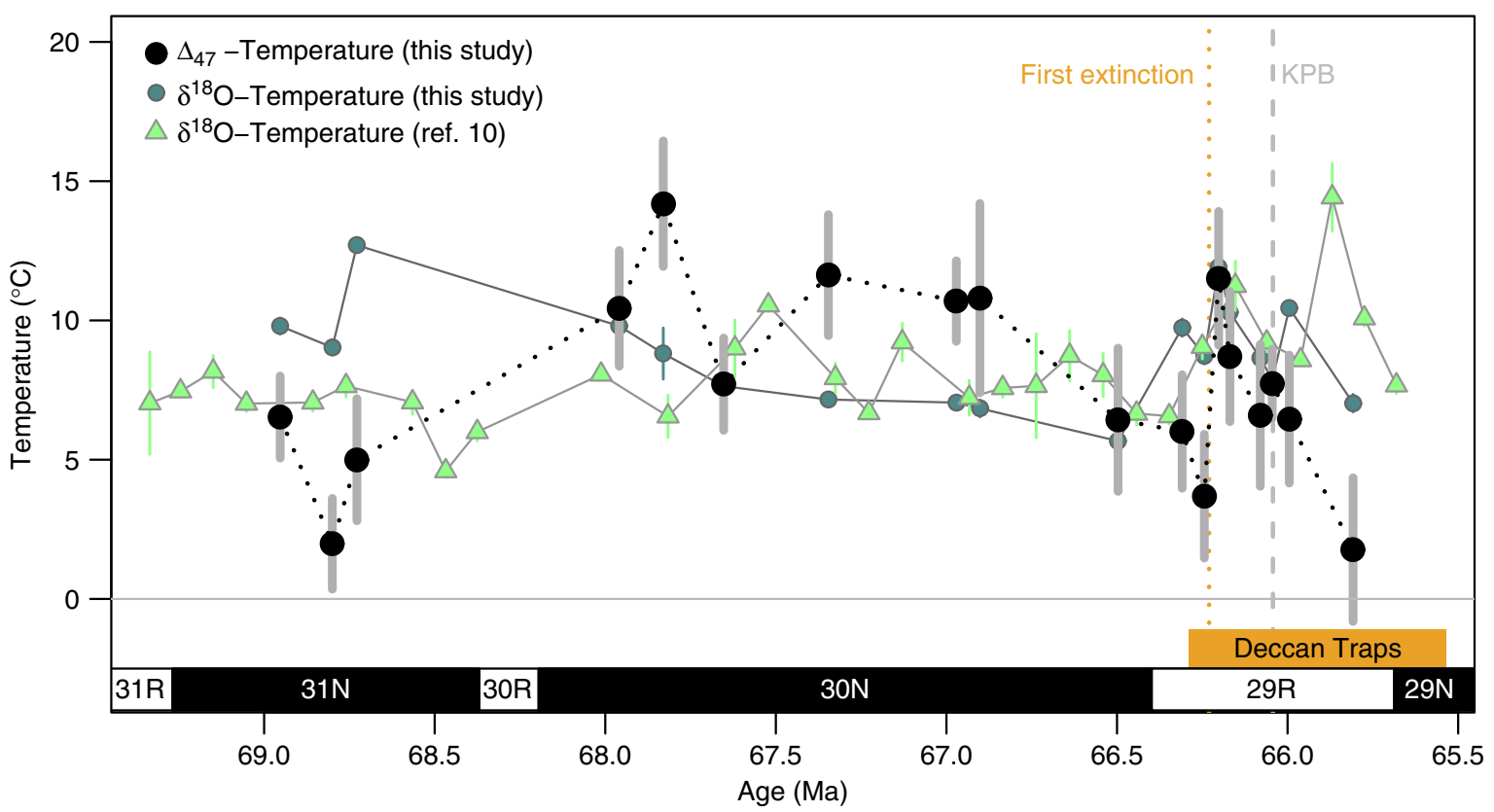

Figure 3 | Comparison of $\boldsymbol{\Delta}_{\mathbf{4 7}}$-derived and $\boldsymbol{\delta}^{\mathbf{1 8}} \mathbf{O}$-derived temperature records. Horizon mean $\boldsymbol{\Delta}_{47}$-derived temperature shown in black with grey error bars (same as Fig. 1a). Horizon mean was calculated as the inverse variance weighted mean, to account for variable reproducibility of samples, with error bars showing the inverse variance weighted error on the mean (see Methods). Line connecting horizon means is dashed to represent extrapolation of temperature trends between measured horizons. Samples within $\pm 3.5 \mathrm{~m}$ stratigraphic position of another sample were combined into a single horizon for horizon means (see Methods). $\delta^{18} \mathrm{O}$-derived temperature calculated from horizon mean $\delta^{18} \mathrm{O}$ (this study) shown in dark turquoise circles with error bars representing $1 \mathrm{~s} . \mathrm{d}$. on $\delta^{18} \mathrm{O}$, propagated through the $\delta^{18} \mathrm{O}-\mathrm{T}-\delta^{18} \mathrm{O}_{\mathrm{w}}$ relationship ${ }^{12}$. Published $\delta^{18} \mathrm{O}$-derived temperature record from Tobin et al. ${ }^{10}$, with age model updated to match this study, shown in light green triangles with error bars representing 1 s.e. on the mean of all sample replicates within a given time bin. Both $\delta^{18} \mathrm{O}$-derived temperature records assume a $\delta^{18} \mathrm{O}_{w}$ value of $-1.0 \%$ (ice-free, globally constant) ${ }^{29}$. If $\delta^{18} \mathrm{O}_{w}$ was instead assumed to be $-1.2 \%$ (ice-free, latitudeadjusted $)^{30}$, the shape of the $\delta^{18} \mathrm{O}$-derived curves would be identical but shifted $\sim 1^{\circ} \mathrm{C}$ colder. The two $\delta^{18} \mathrm{O}$-derived temperature curves miss the million-year $\mathrm{cool} /$ warm/cool temperature structure, underestimate the magnitude of the pre-KPB warming event and infer an earlier timing for the onset of warming, and do not capture the full range of temperatures seen in the $\Delta_{47}$-derived temperature record. Vertical grey dashed line represents the KPg boundary (labelled $\mathrm{KPB})^{34}$ and orange dotted line represents the timing of the first extinction event ${ }^{10}$. Age model construction is described in Methods.

(and therefore probably $\mathrm{CO}_{2}$ emitted) was larger after the $\mathrm{KPB}$, the climatological effects of these emissions were potentially reduced due to higher background $\mathrm{CO}_{2}$ levels and an emissions duration roughly twice as long ${ }^{7,32}$. Additionally, the character of eruptions and the geochemical signature of the lava changed at the $\mathrm{KPB}^{6}$, which could be correlated with changes in the $\mathrm{CO}_{2}$ content and degassing rate. Feedbacks triggered by the meteorite impact may have also played a role in setting temperatures at and after the KPB.

Modelling studies using differing $\mathrm{CO}_{2}$ estimates and injection durations predict $0.5-4{ }^{\circ} \mathrm{C}$ of global warming ${ }^{37-40}$. If the sea icealbedo feedback had the same amplifying impact in Maastrichtian Antarctica as it is having today in the Arctic, the local temperature change could have been as much as double the global value ${ }^{32}$. Roughly $200-400 \mathrm{kyr}$ after the initial large warming event, temperatures at Seymour Island had returned to pre-event levels. This rate of cooling is roughly consistent with the e-folding timescale of silicate weathering ( $\sim 240 \mathrm{kyr}$ (ref. 41$)$ ), supporting the interpretation that this climate change is the result of changes in atmospheric $\mathrm{CO}_{2}$, which would be scrubbed from the atmosphere through this long-term carbon cycle feedback (as well as by other short-term processes).

Species extinction at Seymour Island occurred in two statistically distinguishable pulses ${ }^{10}$, one at the KPg boundary and another one $40 \mathrm{~m}$ below, calculated to be at $66.23 \mathrm{Ma}$ in this age model (Fig. 1a). Early studies of Seymour Island also noted a drop in species diversity $\sim 30 \mathrm{~m}$ below the $\mathrm{KTB}^{8}$. This earlier extinction pulse coincides with the large warming event seen in our record (66.24-66.20 Ma) and with the onset of Chron 29R Deccan Traps volcanism $^{7,33}$. The two extinction intervals are of similar magnitude (14 and 10 species eliminated, respectively), but differ in their extinction patterns, suggesting different kill mechanisms. In the earlier (Deccan) extinction, 9 of 10 species were benthic, whereas in the second (Chicxulub, KPB) extinction, only 6 of 14 species were benthic ${ }^{10}$. Only one ammonite species became extinct in the first event, whereas all remaining (six) ammonite species became extinct at the KPg boundary ${ }^{10,42}$.

The warm temperatures reached at the peak of warming alone could not have caused the first pulse of extinction. Many of the affected species were also present during Chron $30 \mathrm{~N}$ (ref. 10), when temperatures were equivalently warm. Instead, it is possible that the rate of warming, as opposed to the maximum temperatures reached, led to extinction. The rate of warming during the Deccan temperature spike appears to be more rapid than at any other temperature change seen in the record (Fig. 1a), although this may be an artifact of the variable sampling resolution. Other indirect effects of volcanic emissions could also have played a role in the extinction, such as trace metal toxicity ${ }^{2}$, ocean acidification from increased atmospheric $\mathrm{CO}_{2}$, or shortterm cooling and acid rain from emissions of $\mathrm{SO}_{2}$ (ref. 3).

The lowest $\delta^{13} \mathrm{C}$ values are observed in the interval between the pre-KPB and KPB events. Low $\delta^{13} \mathrm{C}$ values have been measured at the KPB from and nearby Seymour Island before ${ }^{16,43}$, which could be an indication of a reduction in surface ocean productivity, as has been previously suggested ${ }^{44-47}$. The difference in temperature between the umbo and ventral margin in Lahillia, a minimum estimate of seasonality, decreased from $5-8^{\circ} \mathrm{C}$ to near $0^{\circ} \mathrm{C}$ after the pre-KPB warming pulse and 
remained low until the end of the study interval. Cucullaea also shows little to no temperature difference between shell positions after the pre-KPB warming event. This could indicate a reduction in seasonality or a reduced growing season due to environmental stresses occurring after the onset of volcanism.

Roughly half of the total species extinction at Seymour Island (10 of 24 species) occurred before the Chicxulub impact event and can be temporally and climatologically linked to Deccan Traps volcanism, indicating the volcanic kill mechanism definitively contributed to the end-Cretaceous extinction. The remaining extinctions (14 of 24 species) took place at the KPg boundary, at the time of the Chicxulub impact, but also the beginning of the post-KPB phase of Deccan volcanism, which was potentially triggered and/or accelerated by the impact itself ${ }^{6,7}$. It is therefore impossible at this point to separate the influences of the meteorite and the additional volcanism in driving the second phase of extinction or in causing the second warming pulse. Nevertheless, the full magnitude of the end-Cretaceous extinction at this site can be attributed to the combined influence of Deccan Traps volcanism and the meteorite impact event, previously described as a presspulse extinction mechanism ${ }^{48,49}$. Importantly, the pre-KPB warming, which itself correlated with significant extinction, may have increased ecosystem stress, making the ecosystem more vulnerable to collapse when the meteorite hit. This sequence of events may have combined into a 'one-two punch' that produced one of the largest mass extinctions in Earth history.

\section{Methods}

Environment and sample selection. Samples are from the W.J. Zinsmeister collection, formerly housed at Purdue University, and now located at the Paleontological Research Institute in Ithaca, NY, USA. Specimens were collected from Seymour Island from the López de Bertodano and Sobral Formations, covering the Late Cretaceous to early Paleocene. The stratigraphic framework used in this study is described by Zinsmeister et al. ${ }^{50}$ and has a stratigraphic resolution of $\pm 3.5 \mathrm{~m}$. Samples come from Units 9 and 10 of the López de Bertodano Formation, part of the upper beds (Units 7-10, Molluscan Units), as defined by Macellari ${ }^{8}$. The Molluscan Units contain diverse and abundant bivalve, gastropod, and ammonite macrofauna. Since the Cretaceous, these sediments are thought to have experienced only mild diagenetic conditions ${ }^{51}$. The depositional environment is interpreted to be inner to outer shelf, a semi-enclosed or quiet environment, with water depths less than $200 \mathrm{~m}$, on the basis of faunal assemblages, grain size and sorting analysis, diversity of macrofauna, and abundance of glauconite ${ }^{8}$. Interpretations of water depth variation through the López de Bertodano Fm. disagree, with some suggesting a shallowing-upward ${ }^{52}$ and others a deepening-upward ${ }^{8}$ trend through the section. Overall, the homogeneous nature of the Molluscan Units 7-9 suggests $8,42,52$, at most, minor variation in water depth over this interval. Although there is some evidence of methane seeps on Seymour and the surrounding islands, it is restricted to lower in the stratigraphy (Units 1-6) ${ }^{53}$. There is no indication of methane seeps in the upper López de Bertodano Formation on Seymour Island ${ }^{43}$.

Bivalve shells (116) were selected from the Zinsmeister collections at Purdue for use in the $\mathrm{PhD}$ thesis of author Andrea Dutton ${ }^{54}$ with the aim of including as many stratigraphic horizons as possible for maximum temporal resolution (the 'full sample set'). Samples were selected from six species (L. larseni, C. antarctica, C. ellioti, E. regina, D. drygalskiana and N. nordenskjoldi) to provide internal consistency between horizons. All these species were thought to live in shallow waters and be infaunal suspension feeders, with the exception of Nordenskjoldia, which is thought to be an epibyssate suspension feeder ${ }^{8}$.

A subset of 29 shells were selected from the full sample set for clumped isotope analysis, representing five of the six species in the original study (eliminating D. drygalskiana; the 'clumped isotope sample set'). These were again selected for maximum stratigraphic coverage and species overlap, but were filtered to only include the best-preserved samples, as indicated by low trace element concentrations (see below). A list of samples in the full sample set and those sub-selected for clumped isotope analysis can be found in Supplementary Data 1.

Sample preparation and extraction. Bulk samples of 50-100 $\mu$ g were drilled from the umbo, mid-shell and ventral margin of all shells in the full sample set for stable isotope and trace element analysis. Samples were drilled to average over multiple growth bands to represent typical mean annual conditions. The umbo position was centred near the cusp of the umbo. The ventral margin ('back') was within $1 \mathrm{~cm}$ of the edge of the shell. The mid-shell position was half way between the umbo and ventral margin. In the case of broken, partial shells, it was not always possible to sample the ventral margin and/or mid-shell position. Broken and partial shells were not selected for the clumped isotope sample set.
The 29 shells selected for clumped isotope analysis were re-drilled in two positions, the umbo and ventral margin. Sampling locations were directly adjacent to earlier drill locations. Sample size requirements for clumped isotope analysis are much larger than for stable isotope analysis ${ }^{11}$, so $20-30 \mathrm{mg}$ of sample material was collected at each position and homogenized. During drilling for clumped isotope analysis, the drill was operated at the lowest possible rotation speed (1,000 r.p.m.) and pressure was only applied for a few seconds at a time to minimize frictional heating. Based on tests with other samples in our lab, at this drill speed, we do not expect to see any resetting effects. Most shells were drilled from the exterior at a position that was clear of external encrustation or fractures. In a few cases, shells were cut in half and were drilled on the cut interior surface. No correlation was seen between measured values and interior versus exterior drilling. Six shells of the genus Eselaevitrigonia were only sampled in the umbo position because invariant stable isotopic compositions between positions suggested that identical environmental conditions were being recorded at all points on the shell (see below), and some shells were broken such that the ventral margin was no longer present.

Trace element analysis. Elemental analysis of $\mathrm{Sr}, \mathrm{Mg}, \mathrm{Ca}, \mathrm{Fe}$ and $\mathrm{Mn}$ was carried out on powdered splits of all bulk samples using either an inductively coupled plasma optical emission spectrophotometer (ICP-OES) or an inductively coupled plasma mass spectrometer (HRICP-MS) depending upon the amount of powdered carbonate available for analysis. Analysis was performed in the Keck Elemental Geochemistry Laboratory at the University of Michigan (Director: K.C. Lohmann). Smaller samples were run on HRICP-MS owing to the lower detection limits attainable on this instrument. By comparison with lab standards and of replicate analyses, precision of both types of analyses was maintained at better than $3 \%$. Because these samples were too small to allow for efficient weight determination, calculation of cation concentrations within the carbonate was achieved by assuming that $\mathrm{Sr}, \mathrm{Mg}, \mathrm{Ca}, \mathrm{Fe}, \mathrm{Mn}$ are carbonate-bound cations and that these five elements account for $100 \%$ of the carbonate-bound cations. Trace element data can be found in Supplementary Data 1.

Assessment of shell preservation. Many lines of evidence (lack of smectite-illite transition, mineralogical and vitrinite-reflectance data) suggest a maximum burial depth of less than $1 \mathrm{~km}$ and a maximum burial temperatures of less than $80^{\circ} \mathrm{C}$ for the López de Bertodano Formation ${ }^{51,55}$. Visual inspection shows shell preservation is excellent, with many shells still displaying pristine mother-of-pearl sheen, indicating the presence of primary aragonite. This was confirmed by conducting $\mathrm{X}$-ray diffraction of powdered material from seven shells representing each of the six species in the full sample set, taken from across the full range of the stratigraphic section. These were shell numbers C1556E (C. antarctica), L776E (L. larseni), D1110I (D. dryganskalia), E1109E (E. regina), N1614C (N. nordenskjoldia), L1161A2 (L. larseni) and C1430 (C. ellioti). In all cases, the mineralogy was completely aragonitic and there was no indication of partial conversion to calcite.

Thick or thin sections were made for nine shells (sample numbers C757C2, L757B, L1480B, L1480E, C1467A, L1529A, C915A2, L1430A1, and L1609). Primary textures, including excellent preservation of growth band structures, were observed in shell carbonate from these sections (Supplementary Fig. 9). These sections were also viewed under cathodoluminescence, which can detect elevated amounts of $\mathrm{Mn}^{2+}$ that may become incorporated in diagenetic carbonate due to post-depositional water-rock interaction. Shells were non-luminescent, except in rare instances where fractures cut across the shell. This observation is particularly notable because it indicates that pore- fluids in the host sediment were reducing and enriched in $\mathrm{Mn}^{2+}$, yet they did not affect bulk shell chemistry. Therefore, alteration is likely only a concern in areas where the shells are fractured. Fractured areas were avoided in sample extraction.

Shell preservation was also assessed through trace element composition. Acceptable levels of Fe and Mn for a well-preserved shell have been determined differently by different authors ${ }^{17,56}$. Conservative trace element thresholds of 500 p.p.m. for Fe and 200 p.p.m. for Mn were set, and samples with concentrations above these were deemed 'potentially altered' and were excluded from further analysis. Of 339 total bulk samples, 42 individual bulk samples (representing 32 unique bivalve shells) had elevated trace element concentrations, indicating overall excellent preservation of samples at Seymour Island.

Shells selected for clumped isotope analysis all had Fe and Mn concentrations below the defined thresholds in the umbo and ventral margin areas. In three cases (N1416B, C772A and C1109A), the trace element composition was only measured at one of the positions on the shell but both positions were sampled for clumped isotopes. In three other cases (C757C-umbo, C915A1-umbo and C915A1-back), the trace element measurements came from the opposite half of the bisected shell, in a mirror image position to where the shell was sampled for clumped isotope analysis. For two shells (L757 and L1430A1), the trace element samples were taken from the outside of the shell, whereas the clumped isotope samples were taken from the inside after the shell was cut in half.

Stable and clumped isotope analysis. Stable carbon and oxygen isotope data were generated for all bulk samples from the full sample set using an automated Kiel device coupled to a Finnigan MAT 251 isotope ratio mass spectrometer in the 
University of Michigan Stable Isotope Laboratory (Director: K.C. Lohmann). Before reaction with phosphoric acid in the Kiel device, individual powdered carbonate samples were first roasted in vacuo at $200^{\circ} \mathrm{C}$ for $1 \mathrm{~h}$ to remove volatile contaminants. Precision of the data was maintained at better than $0.1 \%$ by calibration to carbonate standards (both internal lab standards and NBS-19), measured daily. All carbonate stable isotope compositions are reported relative to Vienna Peedee Belemnite (VPDB). Stable isotope data for bulk samples can be found in Supplementary Data 1 and are shown in Supplementary Figs 5-7.

Samples in the 'clumped isotope sample set' were measured for clumped isotopic composition at the University of Michigan Stable Isotope Laboratory. Carbonate powders were prepared on an offline sample preparation device described by Defliese et al. ${ }^{57}$. Samples measured in 2015 were cleaned using the 'WarmPPQ' configuration, whereas samples measured in 2014 used the 'ColdPPQ' configuration, and were corrected accordingly for fractionations introduced by the Porapak trap ${ }^{58}$.

Standard gases heated to $1,000^{\circ} \mathrm{C}$ and equilibrated with water at $25^{\circ} \mathrm{C}$ were measured alongside samples and were used to define the absolute reference frame ${ }^{59}$. An acid fractionation factor of $0.067 \%$ was used, chosen to reflect the $75^{\circ} \mathrm{C}$ reaction temperature ${ }^{57}$. Two carbonate standard materials, Carrara Marble and Joulter's Cay Ooids, were measured alongside samples. Accepted $\Delta_{47}$ values for these two standards are $0.414 \%$ and $0.704 \%$, respectively ${ }^{57,58}$. Over the three measurement sessions presented here, the mean values for Carrara and Ooids were $0.423 \pm 0.005 \%$ o ( 1 s.e., $n=15$ ) and $0.712 \pm 0.007 \%$ o (1 s.e., $n=13$ ). Raw voltages are converted into delta values following Huntington et al.$^{60}$, including the same defined values for $\lambda$ and for the isotopic composition of VPDB and VSMOW, and $\Delta_{47}$ values were converted to temperature using equation 6 of Defliese et al. ${ }^{57}$.

The stable isotopic composition of the powders in the 'clumped isotope sample set' was measured simultaneously with the measurement of the clumped isotopic composition. Oxygen isotope data were corrected for fractionation during acid digestion using an acid fractionation factor of 1.00836 for aragonitic samples, determined empirically using the aragonitic Ooids carbonate standard, separately calibrated to NBS 18 and NBS-19 (ref. 58). Oxygen isotopic composition of water was calculated using the aragonite-water fractionation of Kim et al. ${ }^{12}$, and is reported relative to VSMOW. Measured clumped isotopic and stable isotopic compositions of 'clumped isotope sample set' shells can be found in Supplementary Data 2-5. Carbonate and gas standard data can be found in Supplementary Data 2-4.

Calculation of sample and horizon averages. Average $\delta^{13} \mathrm{C}$ and $\delta^{18} \mathrm{O}$ values are calculated as the mean of many $(n=2-5)$ replicates, with error taken as 1 s.d. Average values for $\Delta_{47}$, temperature, and $\delta^{18} \mathrm{O}_{\mathrm{w}}$ are taken as the mean of $n$ replicates with the error taken as 1 s.e. on the mean, as is typical in the clumped isotope community (Supplementary Data 5). $\delta^{18} \mathrm{O}_{\mathrm{w}}$ is first calculated individually for each replicate from each $\delta^{18} \mathrm{O}$ and $\Delta_{47}$-derived temperature pair, then mean $\delta^{18} \mathrm{O}_{\mathrm{w}}$ is taken as the mean of many replicates, with 1 s.e. error. In some cases, the calculated 1 s.e. is smaller than the long-term performance of our carbonate standards. We determine 'external error' on $\Delta_{47}$ for a given sample to be the larger of (1) the calculated 1 s.e. of the mean of $n$ replicates or (2) the standard deviation of all replicates of Carrara $(0.019 \%$ ) divided by the square-root of $n$ replicates (Supplementary Data 5). For two to five replicates, this gives a 1 s.e. of $0.013 \%$, $0.011 \%, 0.009 \%$ and $0.008 \%$. The 'external error' on temperature is calculated as half of $T$ (mean $\Delta_{47}$ - extSE.) - T(mean $\Delta_{47}+$ extSE), where $T(x)$ is the $\Delta_{47}-$ Temperature calibration function and 'extSE' is the external s.e. replacing the calculated s.e. Based on typical 1 s.e. values on $\delta^{18} \mathrm{O}_{\mathrm{w}}$ for a sample with a $\Delta_{47}$-error of $0.013 \%, 0.011 \%, 0.009 \%$ and $0.008 \%$, the 'external error' on $\delta^{18} \mathrm{O}_{\mathrm{w}}$ is assigned to be $0.92 \%, 0.78 \%, 0.64 \%$ and $0.57 \%$ for $n=2-5$ replicates, respectively.

External error is used in all figures and calculations for Supplementary Data 6-8.

Most (11 of 18) horizons are represented by two samples taken from different positions on a single shell. Where more than one shell is combined (6 of 18 horizons), all samples are treated equally, regardless of position or shell. Only one horizon is represented by a single position on a single shell (E. regina at $66.9 \mathrm{Ma}$ ). Due to consistently observed patterns within species, we interpret differences between shell positions to reflect environmental aliasing, not scatter around a mean value in a noisy data set. Therefore, the error calculated on a horizon average does not represent certainty on the average value of a noisy data set, but instead represents the spread in data from different shell positions, possibly an indicator of seasonality, combined with some degree of measurement noise. We do not know which species or shell position best represents mean annual temperature, so we felt combining all points equally was the fairest way to treat the data.

Horizon means (Supplementary Data 6-8) are calculated using equation (1) as the inverse variance weighted mean of all samples from a given horizon, combining samples within the uncertainty of the stratigraphy $( \pm 3.5 \mathrm{~m})^{50}$

$$
\text { Inverse variance weighted mean }=\bar{y}=\frac{\sum \frac{y_{i}}{\left(\sigma_{i}\right)^{2}}}{\sum \frac{1}{\left(\sigma_{i}\right)^{2}}}
$$

Error on the horizon mean is calculated using equation (2) as error on an inverse variance weighted mean, to maintain consistency.

$$
\text { Inverse variance weighted mean error }=\sigma^{2}=\frac{1}{\sum \frac{1}{\left(\sigma_{i}\right)^{2}}}
$$

Inverse variance weighted mean was selected to account for the variable reproducibility of samples and not overweight the mean towards a poorly reproducing sample (for example, Sample C1109A at 67.7 Ma). Supplementary Fig. 2 compares multiple methods for calculating horizon mean (for example, inverse variance weighted mean, traditional mean, average of shell averages). The use of traditional mean versus inverse variance weighted mean does not change the long-term pattern, interpretations, or conclusions. The largest difference is seen around $67.7 \mathrm{Ma}$ where there are two poorly reproducing samples.

Taking the average of positions within each shell before combining shells is mathematically equivalent to averaging all points if using the inverse variance weighted mean. Averaging within-shell first only affects four horizons mean minimally at that, if using the traditional mean. We chose to combine adjacent samples based on stratigraphic position, but a composite record could also have been created by combining samples into equal-time bins. Equal-time bins combine samples from before and after the warming spike, resulting in a 'smoothed' temperature record. If the bin size is small enough ( $50 \mathrm{kyr})$, two warming pulses are still observed.

Age model construction. To construct an age model using the recently published magnetostratigraphic data from Seymour Island ${ }^{10}$, the stratigraphic heights of chron reversals were converted to the Zinsmeister stratigraphic framework ${ }^{50}$ based on the established position of the KPg boundary in each $(1,059 \mathrm{~m}$ for this study, 865 for Tobin et al. ${ }^{10}$ ) and assuming equal unit thickness. The stratigraphic height of a point in the Zinsmeister framework is therefore calculated as the height in the Tobin framework plus the difference in the KPg boundary positions $(1,059-865=194 \mathrm{~m})$. This assumption is supported by the position of the Unit 8 -Unit 9 boundary, which is at $652 \mathrm{~m}$ in the Tobin framework ${ }^{10}$. The age model conversion would predict that this Unit boundary should be found at $846 \mathrm{~m}$ in the Zinsmeister framework, and it is described as $\sim 850 \mathrm{~m}$ by Zinsmeister ${ }^{50}$. Based on this close agreement, when comparing extinction events observed in the Tobin framework with climatic events from this study, any events occurring between the base of Unit 8 and the KPB should be in agreement to within $\sim 4 \mathrm{~m}$.

The ages of the relevant chron reversals were taken from the most recent Geological Time Scale (2012) ${ }^{61}$, and the age the KPg boundary was taken as $66.043 \pm 0.043 \mathrm{Ma}$ (ref. 34). The position of chron reversals was taken as the average of the stratigraphic heights of the first sample listed above and below the reversal position ${ }^{10}$. This is different from the age model used by Tobin et al. ${ }^{10}$, which used the 2004 edition of the Geologic Time Scale with the age of the KPg boundary at $65.5 \mathrm{Ma}$. To plot the $\delta^{18} \mathrm{O}$-derived temperature record from Tobin et al. ${ }^{10}$ (Fig. 2), ages for chron reversals were updated to the 2012 Geological Time Scale ${ }^{61}$.

Sample ages were linearly interpolated between age model tie points, listed in Supplementary Table 1. There is inherent uncertainty in magnetostratigraphybased age models due to this interpolation and uncertainties in the construction of the Geological Time Scale ${ }^{61}$. Although not explicitly accounted for, this uncertainty should be considered when comparing events in our age model with absolute U-Pb or ${ }^{40} \mathrm{Ar} /{ }^{39} \mathrm{Ar}$ ages for the Deccan Traps ${ }^{7,33}$.

Strontium isotope analysis. Ten shells were analysed for strontium isotopes for use in corroborating the age model construction. Analyses were performed in the Biogeochemistry and Environmental Isotope Geochemistry Laboratory at the University of Michigan (Director: J.D. Blum). Powdered samples of bivalve aragonite were dissolved in nitric acid and strontium was subsequently separated using ion-exchange chromatography with Eichrom Sr-specific resin. The effluent was dried and loaded onto a tungsten filament for isotope ratio analysis using a Finnigan MAT 262 thermal ionization mass spectrometer. The ${ }^{86} \mathrm{Sr} /{ }^{88} \mathrm{Sr}$ ratio was normalized to 0.1194 and measured ${ }^{87} \mathrm{Sr} /{ }^{86} \mathrm{Sr}$ ratios were corrected for the difference between the long-term laboratory average of NIST 987

$(0.710252 \pm 0.000026(2 \sigma))$ and the accepted value of 0.710248 . Analytical uncertainty was calculated using the standard deviation of NIST 987 over a 12-month period $(2 \sigma=0.000026)$

One sample (L1480B) produced a strontium isotopic composition that is not possible to match to the LOWESS curve at any point between 65 and $69 \mathrm{Ma}$. L1480B also displays anomalously high $\mathrm{Sr} / \mathrm{Ca}$ values $\left(10-20 \mathrm{mmol} \mathrm{mol}^{-1}\right)$, suggesting that it may have been diagenetically altered. Another sample (L1480E) from the same locality produced a reasonable strontium isotope value, so L1480B was ignored. L1480B was also avoided for clumped isotope analysis. Strontium isotope data measured in this study can be found in Supplementary Table 2.

Corroboration of age model with Sr-isotope data. Strontium isotopic data was not used in the creation of the age model described above. These data can, therefore, be used to assess the validity of the age model constructed based on magnetostratigraphy and stratigraphic correlation. In addition to new strontium isotope measurements made on bivalve samples from this study (Supplementary Table 2), strontium isotope data from other Maastrichtian bivalves from the Zinsmeister collection have been previously published (Supplementary Table 3$)^{13}$ Because they come from the same collection, their stratigraphic positions can be directly compared. Ages were calculated for all published samples using the age model described above based on their stratigraphic position in the Zinsmeister stratigraphic framework ${ }^{50}$. Supplementary Fig. 10 shows a comparison of measured 
${ }^{87} \mathrm{Sr} /{ }^{86} \mathrm{Sr}$ values and calculated ages with the most recent seawater strontium isotope curve (LOWESS 5) ${ }^{62}$. There is good agreement between the bivalve data and the seawater curve, lending strong credence to the magnetostratigraphic age model and the stratigraphic conversion between the Zinsmeister framework and the Tobin framework.

Stable isotope trends in the full sample set. In the paper we discuss systematic differences in $\delta^{13} \mathrm{C}$, temperature, and $\delta^{18} \mathrm{O}_{\mathrm{w}}$ between the umbo and back position seen in samples in the clumped isotope sample set (Figs 1 and 2; Supplementary Figs 3,4 and 11). Supplementary Fig. 11 also shows the relationship between position and shell $\delta^{18} \mathrm{O}$. Systematic position-specific behaviour in $\delta^{18} \mathrm{O}$ is complicated due to the competing influences of $\delta^{18} \mathrm{O}_{\mathrm{w}}$ and temperature, which vary together in a way to oppositely influence $\delta^{18} \mathrm{O}$ (Supplementary Fig. 8). Despite this, Cucullaea still consistently shows higher $\delta^{18} \mathrm{O}$ in the ventral margin position, and Lahillia generally shows higher $\delta^{18} \mathrm{O}$ in the umbo position.

Although we cannot look at trends in temperature and $\delta^{18} \mathrm{O}_{\mathrm{w}}$ in the full sample set, we can still look at variation in $\delta^{13} \mathrm{C}$ and $\delta^{18} \mathrm{O}$. In the full sample set, Lahillia and Cucullaea maintain the position-specific relationships in $\delta^{13} \mathrm{C}$ and $\delta^{18} \mathrm{O}$ seen in the limited clumped isotope sample set (Supplementary Figs 5-7). Cucullaea has the highest $\delta^{13} \mathrm{C}$ and $\delta^{18} \mathrm{O}$ values in the ventral margin, whereas Lahillia has the highest $\delta^{13} \mathrm{C}$ and $\delta^{18} \mathrm{O}$ values in the umbo. The consistency in position-specific relationships in the larger data set suggests that the same position-specific behaviour in temperature and $\delta^{18} \mathrm{O}_{\mathrm{w}}$ is likely present in all samples, even if not measured for clumped isotopes.

Nordenskjoldia and Dozyia show similar position-specific relationships in $\delta^{13} \mathrm{C}$ and $\delta^{18} \mathrm{O}$ to Cucullaea and Lahillia, respectively, but of lower total magnitude. Eselaevitrigonia shows a much smaller variation in $\delta^{18} \mathrm{O}$ than Cucullaea or Lahillia and $\delta^{18} \mathrm{O}$ does not correlate to $\delta^{13} \mathrm{C}$ as in the other species. This lower variability in stable isotopes suggests consistent environmental and growth conditions between early and late life for this species. For this reason, Eselaevitrigonia was only sampled in the umbo position. This decision is supported by the small differences in temperature and $\delta^{18} \mathrm{O}_{\mathrm{w}}$ seen in Nordenskjolia, another species showing small variations in stable isotopes (Fig. 1).

Calculations of $\mathbf{C O}_{2}$ emissions from Deccan Traps volcanism. Richards et al. ${ }^{6}$ tentatively place the KPB between the Bushe and Poladpur formations in the Deccan volcanic sequence due to evidence for a hiatus in volcanism and fracturing and faulting in the lower Bushe formation that did not extend into the higher Poladpur formation. This placement is consistent with existing dating of the Deccan Traps, which unfortunately has a sampling gap in the critical region preventing direct placement of the $\mathrm{KPB}^{7,33}$. Assuming this stratigraphic placement of the KPB, we determined an estimate of the minimum and maximum volume of lava erupted between the onset of Chron 29R Deccan volcanism and the KPB, which includes all formations between (and including) Jawhar and Bushe (Kalsubai and Lonavala subgroups).

Estimates of the volume of lava erupted in this interval range from $150 \times 10^{3} \mathrm{~km}^{3}$ (ref. 6) to $500 \times 10^{3} \mathrm{~km}^{3}$ (ref. 35). Using an emission rate of $14 \mathrm{Tg}$ $\mathrm{CO}_{2} \mathrm{~km}^{-3}$ lava ${ }^{34}$, a modern atmospheric mass of $5.15 \times 10^{21} \mathrm{~g}$ and an atmospheric density of $28.966 \mathrm{~g} \mathrm{~mol}^{-1}$ air, these lava volumes equate to 270-900 p.p.m. $\mathrm{CO}_{2}$ emitted to the atmosphere. Compare this to endMaastrichtian atmospheric $\mathrm{CO}_{2}$ levels, which are thought to be $\sim 360-380$ p.p.m. $\mathrm{CO}_{2}$ (ref. 36). The exact timing of lava extrusion during this interval is unknown, but a lack of red boles in the older portion of the section implies very few hiatuses 7,63 . The transient timing of marine carbonate dissolution suggests the main phase of degassing occurred beginning shortly after the onset of Chron 29R and ending within $200 \mathrm{kyr}$ (ref. 37).

We also estimate $\mathrm{CO}_{2}$ emissions during the interval between the KPB and the end of Chron 29R volcanism, which includes the Poladpur to Mahabaleshwar formations (Wai subgroup) based on our hypothetical placement of the KPB. The post-KPB portion of Deccan volcanism emitted another $461 \times 10^{3} \mathrm{~km}^{3}$ (ref. 6) to $500 \times 10^{3} \mathrm{~km}^{3}$ (ref. 35) of lava, equivalent to $830-900$ p.p.m. $\mathrm{CO}_{2}$ added to the atmosphere. The Wai subgroup eruptions contain more red boles ${ }^{7,63}$, suggesting hiatuses between eruptive events. Based on published dates ${ }^{7,33}$, the duration of the post-KPB eruptions is roughly twice the length of the pre-KPB portion $(\sim 500 \mathrm{kyr}$ versus $250 \mathrm{kyr}$ ), although this does not account for potential hiatuses within the eruptive sequence. Although the total volume of lava erupted (and therefore $\mathrm{CO}_{2}$ emitted, based on our assumptions) was larger post-KPB, the climatological impacts might have been smaller due to higher background $\mathrm{CO}_{2}$ levels and a longer duration of eruption. Additionally, the emission rate of $14 \mathrm{Tg} \mathrm{CO}_{2} \mathrm{~km}^{-3} \mathrm{lava}^{35}$ is an average value. Changes in the character of eruptions and the geochemical signature of the lava before and after the Bushe/Poladpur contact (the hypothesized $\mathrm{KPB})^{6}$ could coincide with changes in the lava's $\mathrm{CO}_{2}$ content and therefore emission rate.

Data availability. The data shown and discussed in this paper is presented in full in the Supplementary Material.

\section{References}

1. Courtillot, V. et al. Deccan flood basalts and the Cretaceous/Tertiary boundary. Nature 333, 843-846 (1988).

2. Vogt, P. R. Evidence for global synchronism in mantle plume convection, and possible significance for geology. Nature 240, 338-342 (1972).

3. Self, S., Schmidt, A. \& Mather, T. A. Emplacement characteristics, time scales, and volcanic gas release rates of continental flood basalt eruptions on Earth. Geol. Soc. Am. Bull. 505, 319-337 (2014).

4. Alvarez, L. W., Alvarez, W., Asaro, F. \& Michel, H. V. Extraterrestrial cause for the Cretaceous-Tertiary extinction. Science 208, 1095-1108 (1980).

5. Schulte, P. et al. The chicxulub asteroid impact and mass extinction at the Cretaceous-Paleogene boundary. Science 327, 1214-1218 (2010).

6. Richards, M. A. et al. Triggering of the largest Deccan eruptions by the Chicxulub impact. Geol. Soc. Am. Bull. http://dx.doi.org/10.1130/B31167.1 (2015).

7. Renne, P. R. et al. State shift in Deccan volcanism at the Cretaceous-Paleogene boundary, possibly induced by impact. Science 350, 76-78 (2015).

8. Macellari, C. E. Stratigraphy, sedimentology, and paleoecology of Upper Cretaceous/Paleocene shelf-deltaic sediments of Seymour Island. Geol. Soc. Am. Memoirs 169, 25-54 (1988).

9. Zinsmeister, W. J. \& Macellari, C. E. Bivalvia (Mollusca) from Seymour Island, Antarctic Peninsula. Geol. Soc. Am. Memoirs 169, 253-284 (1988).

10. Tobin, T. S. et al. Extinction patterns, $\delta^{18} \mathrm{O}$ trends, and magnetostratigraphy from a southern high-latitude Cretaceous-Paleogene section: Links with Deccan volcanism. Palaeogeogr. Palaeoclimatol. Palaeoecol. 350, 180-188 (2012).

11. Eiler, J. M. Paleoclimate reconstruction using carbonate clumped isotope thermometry. Quat. Sci. Rev. 30, 3575-3588 (2011).

12. Kim, S. T., O’Neil, J. R., Hillaire-Marcel, C. \& Mucci, A. Oxygen isotope fractionation between synthetic aragonite and water: influence of temperature and $\mathrm{Mg}^{2+}$ concentration. Geochim. Cosmochim. Acta 71, 4704-4715 (2007).

13. McArthur, J. M., Thirwall, M. F., Engkilde, M., Zinsmeister, W. J. \& Howarth, R. J. Strontium isotope profiles across K/T boundary sequences in Denmark and Antarctica. Earth Planet. Sci. Lett. 160, 179-192 (1998).

14. Francis, J. E. \& Poole, I. Cretaceous and early Tertiary climates of Antarctica: evidence from fossil wood. Palaeogeogr. Palaeoclimatol. Palaeoecol. 182, 47-64 (2002).

15. Kemp, D. B. et al. A cool temperature climate on the Antarctic Peninsula through the latest Cretaceous to early Paleogene. Geology 42, 583-586 (2014).

16. Barrera, E., Huber, B. T., Savin, S. M. \& Webb, P.-N. Antarctic marine temperatures: late Campanian through Early Paleocene. Paleoceanography 2, 21-47 (1987)

17. Ditchfield, P. W., Marshall, J. D. \& Pirrie, D. High latitude palaeotemperature variation: new data from the Thithonian to Eocene of James Ross Island, Antarctica. Palaeogeogr. Palaeoclimatol. Palaeoecol. 107, 79-101 (1994).

18. Elorza, J., Gomez Alday, J. J. \& Olivera, E. B. Environmental stress and diagenetic modifications in inoceramids and belemnites from the Upper Cretaceous James Ross basin, Antarctica. Facies 44, 227-242 (2001).

19. Dutton, A., Huber, B. T., Lohmann, K. C. \& Zinsmeister, W. J. High-resolution stable isotope profiles of a Dimitobelid belemnite: Implications for paleodepth habitat and Late Maastrichtian climate seasonality. Palaois 22, 642-650 (2007).

20. Bowman, V. C., Francis, J. E. \& Riding, J. B. Late Cretaceous winter sea ice in Antarctica? Geology 41, 1227-1230 (2013).

21. Wilf, P., Johnson, K. R. \& Huber, B. T. Correlated terrestrial and marine evidence for global climate change before mass extinction at the CretaceousPaleogene boundary. Proc. Natl Acad. Sci. USA 100, 599-604 (2003).

22. Li, L. \& Keller, G. Maastrichtian climate, productivity and faunal turnovers in planktic foraminifera in South Atlantic DSDP sites 525A and 21. Geology 26, 995-998 (1998).

23. MacLeod, K. G., Huber, B. T. \& Isaza-Londoño, C. North Atlantic warming during global cooling at the end of the Cretaceous. Geology 33, 437-440 (2005).

24. Westerhold, T., Rohl, U., Donner, B., McCarren, H. K. \& Zachos, J. C. A complete high-resolution Paleocene benthic stable isotope record for the central Pacific (ODP Site 1209). Paleoceanography 26, PA2216 (2011).

25. Harrington, R. J. Aspects of growth deceleration in bivalves: Clues to understanding the seasonal $\delta^{18} \mathrm{O}$ and $\delta^{13} \mathrm{C}$ record-A comment on Krantz et al. (1987). Palaeogeogr. Palaeoclimatol. Palaeoecol. 70, 399-403 (1989).

26. Buick, D. P. \& Ivany, L. C. 100 years in the dark: extreme longevity of Eocene bivalves from Antarctica. Geology 32, 921-924 (2004).

27. Shone, B. R., Lega, J., Flessa, K. W., Goodwin, D. H. \& Dettman, D. L. Reconstructing daily temperatures from growth rates of the intertidal bivalve mollusk Chione cortezi (northern Gulf of California, Mexico). Palaeogeogr. Palaeoclimatol. Palaeoecol. 184, 131-146 (2002).

28. Ivany, L. C., Wilkinson, B. H. \& Jones, D. S. Using stable isotopic data to resolve rate and duration of growth throughout ontogeny: an example from the surf clam, Spisula solidissima. Palaios 18, 126-137 (2003).

29. Shackleton, N. J. \& Kennett, J. P. Paleotemperature history of the Cenozoic and the initiation of Antarctic glaciation: oxygen and carbon isotope analyses in DSDP Sites 277, 279, and 281. Initial Reports of the Deep Sea Drilling Project 29, 743-755 (1975). 
30. Zachos, J. C., Stott, L. D. \& Lohmann, K. C. Evolution of Early Cenozoic marine temperatures. Paleoceanography 9, 353-387 (1994).

31. Haq, B. U. Cretaceous eustasy revisited. Glob. Planet. Change 113, 44-58 (2014).

32. Screen, J. A. \& Simmonds, I. The central role of diminishing sea ice in recent Arctic temperature amplification. Nature 464, 1334-1337 (2010).

33. Schoene, B. et al. U-Pb geochronology of the Deccan Traps and relation to the end-Cretaceous mass extinction. Science 347, 182-184 (2015).

34. Renne, P. R. et al. Time scales of critical events around the CretaceousPaleogene boundary. Science 339, 684-687 (2013).

35. Self, S., Widdowson, M., Thordarson, T. \& Jay, A. E. Volatile fluxes during flood basalt eruptions and potential effects on the global environment: a Deccan perspective. Earth Planet. Sci. Lett. 248, 518-532 (2006).

36. Beerling, D. J., Lomax, B. H., Royer, D. L., Upchurch, G. R. \& Kump, L. R. An atmospheric $\mathrm{pCO}_{2}$ reconstruction across the Cretaceous-Tertiary boundary from leaf megafossils. Proc. Natl Acad. Sci. USA 99, 7836-7840 (2002).

37. Henehan, M. J., Hull, P. M., Penman, D. E., Rae, J. W. B. \& Schmidt, D. N. Biogeochemical signficiance of pelagic ecosystem function: an end-Cretaceous case study. Phil. Trans. R. Soc. B 371, 1-9 (2016).

38. Caldeira, K. G. \& Rampino, M. R. Deccan volcanism, greenhouse warming, and the Cretaceous/Tertiary boundary. Geol. Soc. Am. Spec. Pap. 247, 117-124 (1990).

39. Caldeira, K. G. \& Rampino, M. R. Carbon dioxide emissions from Deccan volcanism and a K/T boundary greenhouse effect. Geophys. Res. Lett. 17, 1299-1302 (1990).

40. Dessert, C. et al. Erosion of Deccan Traps determined by river geochemistry: impact on the global climate and the Sr-87/Sr-86 ratio of seawater. Earth Planet. Sci. Lett. 188, 459-474 (2001).

41. Colbourn, G. \& Ridgwell, A. The time scale of the silicate weathering negative feedback on atmospheric $\mathrm{CO}_{2}$. Glob. Biogeochem. Cycles 29, 1-14 (2015).

42. Witts, J. D. et al. Evolution and extinction of Maastrichtian (Late Cretaceous) cephalopods from the López de Bertodano Formation, Seymour Island, Antarctica. Palaeogeogr. Palaeoclimatol. Palaeoecol. 418, 193-212 (2015).

43. Tobin, T. S. \& Ward, P. D. Carbon isotope $\left(\delta^{13} C\right)$ differences between Late Cretaceous ammonites and benthic mollusks from Antarctica. Palaeogeogr. Palaeoclimatol. Palaeoecol. 428, 50-57 (2015).

44. Zachos, J. C., Arthur, M. A. \& Dean, W. E. Geochemical evidence for suppression of pelagic marine productivity at the Cretaceous/Tertiary boundary. Nature 337, 61-64 (1989).

45. D'Hondt, S., Donaghay, P., Zachos, J. C., Luttenberg, D. \& Lindinger, M. Organic carbon fluxes and ecological recovery from the Cretaceous-Tertiary mass extinction. Science 282, 276-279 (1998).

46. D'Hondt, S. Consequences of the Cretaceous/Paleogene mass extinction for marine ecosystems. Annu. Rev. Ecol. Evol. Syst. 36, 295-317 (2005).

47. Birch, H. S., Coxall, H. K., Pearson, P. N., Kroon, D. \& Schmidt, D. N. Partial collapse of the marine carbon pump after the Cretaceous-Paleogene boundary. Geology 44, 287-290 (2016).

48. Arens, N. C. \& West, I. D. Press-pulse: a general theory of mass extinction? Paleobiology 34, 456-471 (2008).

49. Arens, N. C., Thompson, A. \& Jahren, A. H. A preliminary test of the press-pulse extinction hypothesis: Palynological indicators of vegetation change preceeding the Cretaceous-Paleogene boundary, McCone County, Montana, USA. Geol. Soc. Am. Spec. Pap. 503, 209-227 (2014).

50. Zinsmeister, W. J. Late Maastrichtian short-term biotic events on Seymour Island, Antarctic Peninsula. J. Geol. 109, 213-229 (2001).

51. Pirrie, D., Ditchfield, P. W. \& Marshall, J. D. Burial diagenesis and pore-fluid evolution in a Mesozoic back-arc basin: the Marambio Group, Vega Island, Antarctica. J. Sediment. Res. A64, 541-552 (1994).

52. Crame, J. A., Francis, J. E., Cantrill, D. J. \& Pirrie, D. Maastrichtian stratigraphy of Antarctica. Cretaceous Res. 25, 411-423 (2004)

53. Little, C. T. S. et al. Late Cretaceous (Maastrichtian) shallow water hydrocarbon seeps from Snow Hill and Seymour Islands, James Ross Basin, Antarctica. Palaeogeogr. Palaeoclimatol. Palaeoecol. 418, 213-228 (2015).

54. Dutton, A. Extracting Paleoenvironmental Records from Molluscan Carbonate. (PhD thesis, University of Michigan, 2002).
55. Palamarczuk, S. et al. Las Formaciones López de Bertodano y Sobral en la Isla Vicecomodoro Marambio, Antártida: IX Congreso Geológico Argentino. Actas 1, 399-419 (1984).

56. Anderson, T. F., Popp, B. N., Williams, A. C., Ho, L.-Z. \& Hudson, J. D. The stable isotopic records of fossils from the Peterborough Member, Oxford Clay Formation (Jurassic), UK: palaeoenvironmental implications. J. Geol. Soc. London 151, 125-138 (1994).

57. Defliese, W. F., Hren, M. T. \& Lohmann, K. C. Compositional and temperature effects of phosphoric acid fractionation on $\Delta_{47}$ analysis and implications for discrepant calibrations. Chem. Geol. 396, 51-60 (2015).

58. Petersen, S. V., Winkelstern, I. Z., Lohmann, K. C. \& Meyer, K. W. The effects of Porapak trap temperature on $\delta^{18} \mathrm{O}, \delta^{13} \mathrm{C}$, and $\Delta_{47}$ values in preparing samples for clumped isotope analysis. Rapid. Commun. Mass Spectrom. 30, 199-208 (2016).

59. Dennis, K. J., Affek, H. P., Passey, B. H., Schrag, D. P. \& Eiler, J. M. Defining an absolute reference frame for 'clumped' isotope studies of $\mathrm{CO}_{2}$. Geochim. Cosmochim. Acta 75, 7117-7131 (2011).

60. Huntington, K. W. et al. Methods and limitations of 'clumped' $\mathrm{CO}_{2}$ isotope $\left(\Delta_{47}\right)$ analysis by gass-source isotope ratio mass spectrometry. J. Mass Spectrom 44, 1318-1329 (2009).

61. Ogg, J. G. in The Geologic Time Scale. (eds Gradstein, F. M., Ogg, J. G., Schmitz, M. D. \& Ogg, G. M.) vol. 1, chap. 5 (Elsevier, Oxford, 2012).

62. McArthur, J. M., Howarth, R. J. \& Shields, G. A. in The Geologic Time Scale. (eds Gradstein, F. M., Ogg, J. G., Schmitz, M. D. \& Ogg, G. M.) vol. 1, chap. 7 (Elsevier, Oxford, 2012).

63. Chenet, A.-L. et al. Determination of rapid Deccan eruptions across the Cretaceous-Tertiary boundary using paleomagnetic secular variation: 2 . Constraints from analysis of eight new sections and synthesis for a 2500-mthick composite section. J. Geophys. Res. 144, B06103 (2009).

\section{Acknowledgements}

We thank W.J. Zinsmeister for contributing his fossil samples and expertise, as well as L. Wingate and $\mathrm{H}$. Ochoa for laboratory support. This work was supported by funding from NSF-OCE-PRF \#1420902, NSF-EAR \#1123733, NSF-OPP \#9318212 and NSF-PLR \#9980538.

\section{Author contributions}

S.V.P. made clumped isotope measurements, interpreted data and wrote manuscript A.D. made stable isotope, trace element, and strontium isotope measurements and helped write manuscript. K.C.L. oversaw all measurements and helped write manuscript.

\section{Additional information}

Supplementary Information accompanies this paper at http://www.nature.com/ naturecommunications

Competing financial interests: The authors declare no competing financial interests.

Reprints and permission information is available online at http://npg.nature.com/ reprintsandpermissions/

How to cite this article: Petersen, S. V. et al. End-Cretaceous extinction in Antarctica linked to both Deccan volcanism and meteorite impact via climate change. Nat. Commun. 7:12079 doi: 10.1038/ncomms12079 (2016)

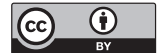

This work is licensed under a Creative Commons Attribution 4.0 International License. The images or other third party material in this article are included in the article's Creative Commons license, unless indicated otherwise in the credit line; if the material is not included under the Creative Commons license, users will need to obtain permission from the license holder to reproduce the material. To view a copy of this license, visit http://creativecommons.org/licenses/by/4.0/

C) The Author(s) 2016 